\title{
Multi-production of high added market value metabolites from diluted methane emissions via methanotrophic extremophiles
}

\author{
S. Cantera ${ }^{a}$, I. Sánchez-Andrea ${ }^{b}$, R. Lebrero ${ }^{a}$, P A. García-Encina ${ }^{a}$, Alfons J.M, \\ Stams $^{\text {b }}$, R. Muñoz ${ }^{\text {** }}$
}

${ }^{a}$ Department of Chemical Engineering and Environmental Technology, School of Industrial Engineering, Valladolid University, Dr. Mergelina, s/n, Valladolid, Spain. ${ }^{b}$ Laboratory of Microbiology, Wageningen University, Stippeneng 4, 6708 WE Wageningen, The Netherlands.

\begin{abstract}
This study is the first proof of concept of a methane biorefinery based on the multiproduction of high profit margin substances (ectoine, hydroxyectoine, polyhydroxyalkanoates (PHAs) and exopolysaccharides (EPS)) using methane as the sole carbon and energy source. Two bubble column bioreactors inoculated with a pure strain (M. alcaliphilum 20Z) and a halophilic methanotrophic consortium (mainly composed of Halomonas, Marinobacter, Methylophaga and Methylomicrobium) were operated under different magnesium concentrations $\left(0.2,0.02\right.$ and $\left.0.002 \mathrm{~g} \mathrm{~L}^{-1}\right)$ with the aim of validating and optimizing this innovative strategy for the valorization of dilute $\mathrm{CH}_{4}$ emissions. High $\mathrm{Mg}^{2+}$ concentrations promoted the accumulation of ectoine (79.7$94.2 \mathrm{mg} \mathrm{g}$ biomass $^{-1}$ ), together with high hydroxyectoine yields (up to $13 \mathrm{mg}$ g biomass ${ }^{1}$ ) and EPS (up to $2.6 \mathrm{~g} \mathrm{~g}$ biomass $^{-1}$ ). Unfortunately, PHA synthesis was negligible at 0.2 and $0.02 \mathrm{~g} \mathrm{Mg}^{2+} \mathrm{L}^{-1}$, and supported low PHAs concentrations (14.3 $\mathrm{mg} \mathrm{L}^{-1}$ ) at the lowest $\mathrm{Mg}^{2+}$ concentrations. The elimination capacities of methane in both bioreactors
\end{abstract}


ranged from 15 to $20 \mathrm{~g} \mathrm{~m}^{-3} \mathrm{~h}^{-1}$ at 0.2 and $0.02 \mathrm{~g} \mathrm{Mg}^{2+} \mathrm{L}^{-1}$, even if the most representative genera have not been previously identified as methanotrophs before. The promising results here obtained encourage further research on $\mathrm{CH}_{4}$ biorefineries capable of creating value out of GHG mitigation.

Keywords: $\mathrm{CH}_{4}$-biorefinery, ectoines, exopolysaccharides, Halomonas, methane abatement.

\section{Introduction}

Methane $\left(\mathrm{CH}_{4}\right)$ is nowadays the second most important greenhouse gas (GHG) as a result of its high global warming potential (85 times higher than that of $\mathrm{CO}_{2}$ over a 20 -y window) and emission rates. Despite $\mathrm{CH}_{4}$ can be used as an energy vector for electricity and heat generation when its concentration in the gas emission is higher than $20 \%$, more than $60 \%$ of anthropogenic $\mathrm{CH}_{4}$ emissions worldwide contain concentrations lower than $4 \%^{1,2}$. When applied to these diluted gas emissions (such as off-gases from landfills or coal mines), state-of-the-art physical/chemical technologies for $\mathrm{CH}_{4}$ abatement are neither environmentally friendly nor cost-effective ${ }^{3}$.

Nowadays, the lack of a suitable approach to prevent the adverse environmental effects of $\mathrm{CH}_{4}$ has encouraged both political initiatives to control these GHG emissions and an intensive research on novel strategies for $\mathrm{CH}_{4}$ abatement ${ }^{4}$. Of them, the bioconversion of $\mathrm{CH}_{4}$ into high added value products using a bio-refinery approach has emerged as one of the most promising ones ${ }^{5-7}$. In this regard, $\mathrm{CH}_{4}$-laden emissions can be used by methanotrophs as feedstock to synthesize bioproducts with a high profit margin, such as 
biopolymers, exopolysaccharides or ectoines, turning $\mathrm{CH}_{4}$ emissions abatement into a sustainable and profitable process.

Ectoine and its hydroxylated derivative (hydroxyectoine) are one of the most valuable bioproducts synthesised by microorganisms, retailing in the pharmaceutical industry at approximately US $\$ 1000 \mathrm{~kg}^{-1}$. These compatible solutes, which are synthesized by bacteria to survive in salt-rich environments, are effective stabilizers for enzymes, DNA-protein complexes and nucleic acids ${ }^{8}$. Recent studies have demonstrated that Methylomicrobium alcaliphilum 20Z, an alkalophilic and halotolerant methanotroph, is able to produce ectoine at $37-70 \mathrm{mg} \mathrm{L}^{-1}$ under continuous $\mathrm{CH}_{4}$ fermentation ${ }^{9}$. However, the ectoine productivities obtained in bioreactors by methanotrophs are still low in comparison with those reported for heterotrophic bacteria such as Halomonas elongate and Halomonas salina ${ }^{8}$. Moreover, the halophilic methanotrophs discovered to date are sensitive to shear stress, which entails the need for bioreactor operation at low agitation rates, thus hampering the mass transfer of $\mathrm{CH}_{4}$ to the microbial community ${ }^{10}$. Finally, it should be stressed that hydroxyectoine accumulation by methanotrophs has never been reported to date ${ }^{11}$.

Polyhydroxyalkanoates (PHAs) are intracellular biopolyesters produced under nutrientlimiting and carbon-excess conditions as carbon and energy storage resources by a wide range of microorganisms ${ }^{12}$. Their outstanding mechanical properties, along with their biodegradability and biocompatibility, turns PHAs into an attractive and potential alternative to oil-based plastics ${ }^{5,13}$. Under nutrient-limiting conditions (i.e $\mathrm{N}-, \mathrm{P}-$ or $\mathrm{Mg}$ limitation), methanotrophic bacteria are able to reach PHAs accumulations ranging from 20 up to $50 \%$ (on a dry weight basis) in suspended growth bioreactors operated under batch $^{14,15}$ and continuous mode ${ }^{16}$. 
On the other hand, extracellular polysaccharides (EPS) constitute another potential high added value bioproduct resulting from $\mathrm{CH}_{4}$ biorefineries. These biopolymers, in which biofilms are embedded, are composed of a wide variety of proteins, glycoproteins, glycolipids and polysaccharides ${ }^{17}$. EPS are typically excreted by bacteria under stress conditions as a protective barrier or water retainer. The interest in these novel bioproducts derive from their colloid and adhesive properties, and their effects on liquid rheology, gaining relevance in the food, pharmaceutical, textile and oil industries ${ }^{18}$. To date, some studies have demonstrated that methanotrophic bacteria are able to synthesize EPS in the range of $0.03-0.43 \mathrm{~g} \mathrm{~g}^{-1}$ biomass ${ }^{19}$.

In this context, the present study represents an assessment of the potential of the continuous bioconversion of $\mathrm{CH}_{4}$ into multiple added-value products (i.e ectoine, hydroxyectoine, PHAs and EPS) as an innovative strategy for the valorization of diluted $\mathrm{CH}_{4}$ emissions. For this purpose, a systematic comparison of the performance of two bubble column bioreactors inoculated with haloalkaliphilic methanotrophs, a pure strain M. alcaliphilum $20 \mathrm{Z}$ and an enriched haloalkaliphilic consortium, was carried out. The influence of magnesium $\left(\mathrm{Mg}^{2+}\right)$ concentration on the synthesis of the target bioproducts and on the structure of the bacterial communities was evaluated.

\section{Materials and Methods}

\subsection{Chemicals and mineral salt medium}

The mineral salt medium (MSM) used for the cultivation of the haloalkaliphilic methanotrophs in this study was a high $\mathrm{pH}(9.0)$ and high-salt content $(6 \% \mathrm{NaCl})$ medium recommended for the enrichment of methane oxidizing bacteria from soda lakes. ${ }^{20}$ Magnesium was supplemented to the MSM in the form of $\mathrm{MgSO}_{4}$ at the 3 
concentrations tested $\left(0.2(\mathrm{C} 1), 0.02(\mathrm{C} 2), 0.002(\mathrm{C} 3) \mathrm{g} \mathrm{L}^{-1}\right)$. The limitation of $\mathrm{Mg}^{2+}$ in $\mathrm{C} 2$ and $\mathrm{C} 3$ was carried out with the aim of increasing PHAs production according to Khanna et al. $(2005)^{21}$. Nitrogen limitation was not tested due to the negative effect on ectoine and hydroxyectoine production. All chemicals and reagents were obtained from Panreac (Barcelona, Spain) with a purity higher than $99.0 \% . \mathrm{CH}_{4}$ (purity of at least $99.5 \%$ ) was purchased from Abello-Linde S.A (Barcelona, Spain).

\subsection{Microorganisms and inocula preparation}

Reactor 1 (R1) was inoculated with a pure strain of M. alcaliphilum $20 Z$ acquired from DSMZ (Leibniz-Institut). In brief, a 10× dilution of the M. alcaliphilum $20 Z$ stock culture from DSMZ was grown at $25^{\circ} \mathrm{C}$ in $120 \mathrm{~mL}$ sterile glass bottles containing 40 $\mathrm{mL}$ of MSM at $0.2 \mathrm{~g} \mathrm{MgSO}_{4} \mathrm{~L}^{-1}$. The bottles were closed with gas-tight butyl septa and aluminum caps, and $50 \%(\mathrm{v} / \mathrm{v})$ of the air headspace was replaced by $\mathrm{CH}_{4}$. The inoculum, which was grown up to a biomass concentration of $0.1 \pm 0.06 \mathrm{~g}$, was transferred to two sterile gas-tight glass bottles $(1.2 \mathrm{~L})$ closed with butyl septa and plastic screw caps, and containing $180 \mathrm{~mL}$ of $\mathrm{MSM}$ at $0.2 \mathrm{~g} \mathrm{MgSO}_{4} \mathrm{~L}^{-1}(20 \mathrm{~mL}$ per bottle) prior reactor inoculation. $\mathrm{CH}_{4}$ was injected to obtain a $\mathrm{CH}_{4}$ headspace concentration of $55.0 \pm 6.2 \mathrm{~g} \mathrm{CH}_{4} \mathrm{~m}^{-3}$. The magnetic agitation rate was set at $600 \mathrm{rpm}$ and the temperature used was $25^{\circ} \mathrm{C}$.

Reactor 2 (R2) was inoculated with an enrichment of haloalkaliphilic bacteria able to grow using methane as the only external carbon and energy source. Fresh activated sludge from a denitrification-nitrification wastewater treatment plant with seawater intrusion (Cantabria, Spain) and fresh cow manure and soil from a dairy farm on the coastline of Cantabria (Spain) were used as inoculum for the enrichment. Culture enrichment was carried in two sterile gas-tight glass bottles (1.2 L) containing $190 \mathrm{~mL}$ of MSM at $0.2 \mathrm{~g} \mathrm{MgSO}_{4} \mathrm{~L}^{-1}$ inoculated with $10 \mathrm{~mL}$ of the cow manure-soil mixture and 
$10 \mathrm{~mL}$ of the activated raw sludge. The bottles were closed with butyl septa and plastic screw caps, and $\mathrm{CH}_{4}$ was injected to obtain a $\mathrm{CH}_{4}$ headspace concentration of $55.1 \pm$ $2.7 \mathrm{~g} \mathrm{CH}_{4} \mathrm{~m}^{-3}$. The enrichments were transferred 7 times to fresh medium bottles upon $\mathrm{CH}_{4}$ depletion using $10 \%$ inoculum aliquots. The magnetic agitation rate was set at 600 rpm and the temperature used was $25^{\circ} \mathrm{C}$.

\subsection{Experimental set-up and operating conditions}

Two 2.0 L bubble column reactors (Afora S.A., Spain) were used for continuous $\mathrm{CH}_{4}$ abatement combined with the co-production of ectoines, EPS and PHAs. The influence of three different $\mathrm{Mg}^{2+}$ concentrations $\left(0.2 \mathrm{~g} \mathrm{~L}^{-1}, 0.02 \mathrm{~g} \mathrm{~L}^{-1}\right.$ and $\left.0.002 \mathrm{~g} \mathrm{~L}^{-1}\right)$ on production of the above mentioned bioproducts was assessed in both reactors during stages C1, C2 and C3, respectively. R1 was inoculated with M. alcaliphilum $20 \mathrm{Z}$ at an initial concentration of $520 \mathrm{mg} \mathrm{L}^{-1}$, while $\mathrm{R} 2$ was inoculated with the haloalkaliphilic bacteria enrichment at $500 \mathrm{mg} \mathrm{L}^{-1}$. A $0.066 \mathrm{~L} \mathrm{~min}^{-1} \mathrm{CH}_{4}$-laden air emission containing $25.9 \pm 2.1 \mathrm{~g} \mathrm{CH}_{4} \mathrm{~m}^{-3}(\approx 4 \%)$, corresponding to a methane load of $51.3 \pm 2.2 \mathrm{~g} \mathrm{~m}^{-3} \mathrm{~h}^{-1}$, was fed into R1 and R2 via three $10 \mu \mathrm{m}$ porous stainless steel diffusers located at the bottom of the reactors. The stream was obtained by mixing a pure $\mathrm{CH}_{4}$ stream (controlled by means of a mass flow controller, Aalborg, USA) with a pre-humidified air flow, resulting in a gas empty bed residence time (EBRT) of $30 \mathrm{~min}$ in the reactors. Both reactors were operated at $25^{\circ} \mathrm{C}$ and a $\mathrm{pH}$ of $9.0 \pm 0.3$, which was maintained via daily replacement of MSM at a dilution rate of $0.05 \mathrm{~d}^{-1}$. The cultivation broth aliquots of $100 \mathrm{~mL}$ daily drawn from the reactors were used for the determination of the concentrations of biomass (measured as total suspended solids (TSS)), ectoine, hydroxyectoine, EPS and PHAs. Gas samples were also periodically taken using gastight syringes (HAMILTON, Australia) from the sampling ports located at the inlet and outlet of the bioreactors for the determination of $\mathrm{CH}_{4}$ and $\mathrm{CO}_{2}$ gas concentrations. The 
elimination capacity (EC, $\mathrm{g} \mathrm{m}^{-3} \mathrm{~h}^{-1}$ ) and removal efficiency (RE, \%) of the bioreactors were calculated as described by Nikiema et al. (2007) ${ }^{22}$ Steady state operation was achieved when neither the EC nor RE deviated $>10 \%$ from the mean.

A mass transfer test was carried out under steady state at the end of C1, C2 and C3 in order to elucidate the limiting step during $\mathrm{CH}_{4}$ biodegradation under the experimental conditions evaluated. For this purpose, the inlet $\mathrm{CH}_{4}$ concentration was increased from $25.9 \pm 2.1 \mathrm{~g} \mathrm{~m}^{-3}$ to $52.9 \pm 3.6 \mathrm{~g} \mathrm{~m}^{-3}$ for a period of $6 \mathrm{~h}$, and the concomitant variations in $\mathrm{EC}$ and $\mathrm{CO}_{2}$ production were periodically recorded ${ }^{23}$. In this context, an increase in the inlet concentration of methane by a factor of 2 would result in 2 time higher $\mathrm{CH}_{4}$ mass flow rates potentially available for the microbial community. Under a microbial activity limiting scenario, not enough bacteria would be available to degrade this additional methane load and therefore the EC would remain constant (similar to the EC before the increase in the $\mathrm{CH}_{4}$ inlet load). However, if the process was limited by the mass transfer of $\mathrm{CH}_{4}$ to the microbial community, the EC would eventually increase by a factor of 2 as a result of the higher $\mathrm{CH}_{4}$ concentration gradient available for $\mathrm{CH}_{4}$ mass transfer and the availability of a microbial community active enough to cope with this additional $\mathrm{CH}_{4}$ load.

\subsection{Analytical procedures}

The intra-cellular ectoine and hydroxyectoine concentration was determined using $2 \mathrm{~mL}$ of cultivation broth according to Cantera et al. $(2016 \mathrm{~b})^{24}$. The specific intra-cellular concentrations ( $\mathrm{g}$ ectoine or $\mathrm{g}$ hydroxyectoine $\mathrm{g}$ biomass $^{-1}$ ) were calculated using the TSS concentration $\left(\mathrm{g} \mathrm{L}^{-1}\right)$ of the corresponding cultivation broth, which was determined according to Standard methods ${ }^{25}$. The measurement was carried out by high performance liquid chromatography in a HPLC 717 plus auto-sampler (Waters, Bellefonte, USA) coupled with a UV Dual $\lambda$ Absorbance detector (Waters, Bellefonte, 
USA) at $210 \mathrm{~nm}$ and $40{ }^{\circ} \mathrm{C}$ using a LC-18 AQ + C Supelcosil column (Waters, Bellefonte, USA) and a C18 AQ + pre-column (Waters, Bellefonte, EEUU). A phosphate buffer, consisting of $0.8 \mathrm{mM} \mathrm{K}_{2} \mathrm{HPO}_{4}$ and $6.0 \mathrm{mM} \mathrm{Na} 2 \mathrm{HPO}_{4}$, was used as a mobile phase at $40{ }^{\circ} \mathrm{C}$ and a flow rate of $1 \mathrm{~mL} \mathrm{~min}^{-1}{ }^{26}$. Ectoine and hydroxyectoine quantification was carried out using external standards of commercially available ectoine and hydroxyectoine with a purity of $95 \%$ (Sigma Aldrich, Spain).

PHAs analysis was carried out by centrifuging cultivation broth samples of $2 \mathrm{~mL}$ for 5 min at $9000 \mathrm{~g}$ and further processing the pellet according to López et al. (2014) ${ }^{27}$. The PHAs extracted from the samples were measured in a 7820A GC coupled with a 5977E MSD (Agilent Technologies, Santa Clara, USA) and equipped with a DB-wax column (30 $\mathrm{m} \times 250 \mu \mathrm{m} \times 0.25 \mu \mathrm{m})$. The detector and injector temperatures were maintained at $250{ }^{\circ} \mathrm{C}$. The oven temperature was initially maintained at $40{ }^{\circ} \mathrm{C}$ for $5 \mathrm{~min}$, increased at $10{ }^{\circ} \mathrm{C} \min ^{-1}$ up to $200{ }^{\circ} \mathrm{C}$ and maintained at this temperature for 2 min. Finally, the oven temperature was increased up to $240{ }^{\circ} \mathrm{C}$ at a rate of $5{ }^{\circ} \mathrm{C} \mathrm{min}^{-1}$. The PHA content of the samples was referred to the volume of the corresponding cultivation broth used for analysis.

For EPS measurement, $0.5 \mathrm{~mL}$ of supernatant (after centrifugation for PHA analysis) were placed in a new dry and pre-weighted Eppendorf. The EPS fraction of the bacterial supernatant was precipitated by adding $1.5 \mathrm{~mL}$ of ethanol $90 \%(\mathrm{v} / \mathrm{v})$ followed by an overnight incubation period. After incubation, the sample was centrifuged at $9000 \mathrm{~g}$ for 20 minutes and the supernatant was discarded. The sample was dried for 24 hours at 58 ${ }^{\circ} \mathrm{C}$ and the mass of the precipitated EPS determined gravimentrically ${ }^{28}$. The EPS content of the samples was referred to the volume of the corresponding cultivation broth used for analysis. 
Gas concentrations of $\mathrm{CH}_{4}$ and $\mathrm{CO}_{2}$ were determined in a Bruker 430 GC-TCD (Palo Alto, USA) equipped with a CP-Molsieve 5A $(15 \mathrm{~m} \times 0.53 \mu \mathrm{m} \times 15 \mu \mathrm{m})$ and a CPPoraBOND Q $(25 \mathrm{~m} \times 0.53 \mu \mathrm{m} \times 10 \mu \mathrm{m})$ column. The oven, injector and detector temperatures were maintained at $45^{\circ} \mathrm{C}, 150^{\circ} \mathrm{C}$ and $200^{\circ} \mathrm{C}$, respectively. Helium was used as the carrier gas at $13.7 \mathrm{~mL} \mathrm{~min}^{-1}$.

\subsection{Data analysis}

The statistical data analysis was performed using SPSS 20.0 (IBM, USA). The results are given as the average \pm standard deviation. The homogeneity of the variance of the parameters was evaluated using a Levene test. Significant differences were analysed by ANOVA and post-hoc analysis for multiple group comparisons. Differences were considered to be significant at $\mathrm{p} \leq 0.05$.

\subsection{Bacterial community analysis}

Aliquots of $5 \mathrm{~mL}$ of the cultivation broths from the reactors under steady state were centrifuged at $9000 \mathrm{~g}$ for $10 \mathrm{~min}$ (Table 1). The resting pellet was used for DNA extraction with the FastDNA SPIN Kit for Soil (MP Biomedicals, Solon, OH) according to the manufacturer's instructions. DNA was quantified with a Nanodrop spectrophotometer (Nanodrop Technologies, Wilmington, DE). The microbial composition of the 6 independently amplified reactor samples and mixed inoculum (Table 1) was characterized by sequencing two variable $16 \mathrm{~S}$ rRNA gene regions, V4 and V5, in three separate sequencing runs on Illumina's HiSeq2000 platform using the 515f/926r primer pair according to Waters et al., $2017^{29}$. The microbial composition of the inoculum of R1 was not analysed since it was inoculated with a pure culture of $M$. alcaliphilum $20 \mathrm{Z}$ grown under sterile conditions. Illumina fastq files were demultiplexed, quality filtered and analysed using QIIME (v. 1.9). For this purpose, different default settings and quality parameters were used according to Ramiro-García 
et al. (2016) ${ }^{30}$. The $16 \mathrm{~S}$ rRNA gene amplicons were filtered for quality $(\mathrm{Q}>25)$ and size (>200 bp), and phylogenetically classified ${ }^{30}$. The reference database used for taxonomic assignment was the SILVA database version $123^{31}$.

\section{Results}

\subsection{Influence of $\mathrm{Mg}^{2+}$ concentration on ectoine production}

The synthesis of intra-cellular ectoine under steady state was clearly influenced by $\mathrm{Mg}^{2+}$ concentration in both reactors. $\mathrm{A} \mathrm{Mg}^{2+}$ concentration of $0.2 \mathrm{~g} \mathrm{~L}^{-1}$ was identified as the optimum value for the accumulation of intra-cellular ectoine, supporting average specific contents of $94.2 \pm 10.1$ and $79.7 \pm 5.1 \mathrm{mg}^{\text {ectoine }} \mathrm{g}$ biomass $^{-1}$ in R1 and R2, respectively. Lower $\mathrm{Mg}^{2+}$ concentrations supported lower ectoine yields: $51.0 \pm 3.9$ and $54.9 \pm 3.5 \mathrm{mg}$ ectoine $\mathrm{g}$ biomass $^{-1}$ in $\mathrm{C} 2$ and $35.0 \pm 2.2$ and $19.7 \pm 0.8 \mathrm{mg}$ ectoine $\mathrm{g}$ biomass $^{-1}$ in $\mathrm{C} 3$ in $\mathrm{R} 1$ and $\mathrm{R} 2$, respectively.

\section{$<$ Figure 1>}

\subsection{Influence of $\mathrm{Mg}^{2+}$ concentration on hydroxyectoine production}

$\mathrm{Mg}^{2+}$ concentration also exerted a significant influence on the synthesis of this osmoprotectant (Figure 2). $\mathrm{Mg}^{2+}$ concentrations of $0.2 \mathrm{~g} \mathrm{~L}^{-1}$ mediated the accumulation of average concentrations of $13.3 \pm 0.7 \mathrm{mg}$ hydroxyectoine $\mathrm{g}$ biomass $^{-1}$ in $\mathrm{R} 2$, while lower $\mathrm{Mg}^{2+}$ concentrations supported lower hydroxyectoine yields in the same reactor: $9.05 \pm 0.3$ and $3.8 \pm 0.1 \mathrm{mg}$ hydroxyectoine $\mathrm{g} \mathrm{biomass}^{-1}$ in $\mathrm{C} 2$ and $\mathrm{C} 3$ respectively. Interestingly, hydroxyectoine was only detected in $\mathrm{R} 1$ at the lowest $\mathrm{Mg}^{2+}$ concentration $\left(2.5 \pm 0.2 \mathrm{mg}\right.$ hydroxyectoine $\mathrm{g}$ biomass $^{-1}$ in $\left.\mathrm{C} 3\right)$.

$<$ Figure 2>

\subsection{Influence of $\mathrm{Mg}^{2+}$ concentration on PHA production}


PHAs were detected in the biomass present in both reactors at the three $\mathrm{Mg}^{2+}$ concentrations tested. The highest $\mathrm{Mg}^{2+}$ concentrations negatively impacted the accumulation of PHAs in R1 $\left(1.3 \pm 0.1\right.$ and $1.8 \pm 0.1 \mathrm{mg} \mathrm{PHA} \mathrm{L}^{-1}$ culture broth $^{-1}$ in $\mathrm{C} 1$ and C2, respectively), since biopolymers are generally produced under nutrient limiting conditions. Likewise, $\mathrm{Mg}^{2+}$ concentrations of $0.002 \mathrm{~g} \mathrm{~L}^{-1}$ induced the accumulation of PHAs up to average values of $14.6 \pm 0.5 \mathrm{mg}$ PHAs $\mathrm{L}^{-1}$ culture broth ${ }^{-1}$ in $\mathrm{R} 1$. In the particular case of $\mathrm{R} 2, \mathrm{Mg}^{2+}$ concentration did not influence PHAs accumulation in the tested range $\left(1.9 \pm 0.1,2.4 \pm 0.1\right.$ and $2.4 \pm 0.1 \mathrm{mg} \mathrm{PHA} \mathrm{L} \mathrm{culture} \mathrm{broth}{ }^{-1}$ in $\mathrm{C} 1, \mathrm{C} 2$ and C3, respectively).

\section{$<$ Figure 3>}

\subsection{Influence of $\mathrm{Mg}^{2+}$ concentration on EPS production}

EPS synthesis was also significantly influenced by $\mathrm{Mg}^{2+}$ concentration in both bioreactors. Hence, $0.2 \mathrm{~g} \mathrm{Mg}^{2+} \mathrm{L}^{-1}$ was identified as the optimum concentration for the synthesis of EPS, which reached yields of $1833 \pm 87$ and $2642 \pm 83 \mathrm{mg}$ EPS g biomass ${ }^{-1}$ in $\mathrm{R} 1$ and $\mathrm{R} 2$, respectively (Figure 4). A decrease in $\mathrm{Mg}^{2+}$ concentration resulted in lower EPS yields: $1000 \pm 124$ and $757 \pm 53$ mg EPS g biomass ${ }^{-1}$ in C2 and $952 \pm 62$ and $477 \pm 47 \mathrm{mg}^{\mathrm{EPS}} \mathrm{g}$ biomass $^{-1}$ in C3 in R1 and R2, respectively.

\section{$<$ Figure 4>}

\subsection{Influence of $\mathrm{Mg}^{2+}$ concentration on $\mathrm{CH}_{4}$ abatement performance}

ECs of $16.1 \pm 1.1,18.9 \pm 0.9$ and $12.2 \pm 0.3 \mathrm{~g} \mathrm{~m}^{-3} \mathrm{~h}^{-1}$ (corresponding to REs of $26.8 \pm$ $1.8,36.0 \pm 1.9$ and $20.8 \pm 0.4 \%$ ) were recorded in $\mathrm{R} 1$ at $0.2,0.02$ and $0.002 \mathrm{~g} \mathrm{Mg}^{2+} \mathrm{L}^{-}$ ${ }^{1}$, respectively, while ECs of $16.2 \pm 1.1,15.05 \pm 0.4$ and $11.2 \pm 0.7 \mathrm{~g} \mathrm{~m}^{-3} \mathrm{~h}^{-1}$ (corresponding to REs of $25.3 \pm 1.1,25.8 \pm 0.6$ and $18.5 \pm 1.2 \%$ ) were recorded in $\mathrm{R} 2$ under similar $\mathrm{Mg}^{2+}$ concentrations (Figure 5). The mass transfer limitation tests conducted at the three $\mathrm{Mg}^{2+}$ concentrations tested revealed that an average increase in 
the $\mathrm{CH}_{4}$ inlet load of 2.2 resulted in a $\times 1.8 \pm 0.12$ increase in the EC in both reactors (Table S1. Supplementary Material). The fact that the higher $\mathrm{CH}_{4}$ concentration gradient mediated by the increase in inlet $\mathrm{CH}_{4}$ concentrations supported higher ECs in both bioreactors confirmed that process operation was limited by $\mathrm{CH}_{4}$ mass transfer regardless the $\mathrm{Mg}^{2+}$ concentration tested ${ }^{32}$. Moreover, biomass concentrations did not show significant differences among the three $\mathrm{Mg}^{2+}$ concentrations tested in $\mathrm{R} 1$ (TSS concentrations of $1.2 \pm 0.3,1.7 \pm 0.3,1.7 \pm 0.2 \mathrm{~g} \mathrm{~L}^{-1}$ in $\mathrm{C} 1, \mathrm{C} 2$ and $\mathrm{C} 3$, respectively) and R2 (TSS concentration of $1.3 \pm 0.2,1.1 \pm 0.5,1.7 \pm 0.3 \mathrm{~g} \mathrm{~L}^{-1}$ in $\mathrm{C} 1, \mathrm{C} 2$ and $\mathrm{C} 3$, respectively).

\section{$<$ Figure 5>}

\subsection{Influence of $\mathrm{Mg}^{2+}$ concentration on the structure of bacterial population}

Despite R1 was inoculated with a pure culture of M. alcaliphilum 20Z, the genus Methylomicrobium only represented $63 \pm 2 \%$ of the total bacterial population by the end of C1. At this stage, the genera Methylophaga, Gelidibacter, Marinobacter and Halomonas were also present in R1, with abundances of $12 \pm 1 \%, 5 \pm 0,5 \pm 1 \%, 2 \pm 0$ $\%$, respectively (Figure 6). The reduction of $\mathrm{Mg}^{2+}$ concentration in the MSM to 0.02 $\mathrm{Mg}^{2+} \mathrm{L}^{-1}$ gradually impacted on the population structure of $\mathrm{R} 1$ by the end of $\mathrm{C} 2$, Methylophaga $(20 \pm 2 \%)$, Gelidibacter $(18 \pm 8 \%)$, Marinobacter $(5 \pm 1 \%)$, and Halomonas $(4 \pm 1 \%$ ) overcoming the genus Methylomicrobium to a $3 \pm 1 \%$ of the total bacterial population. Finally, the lowest $\mathrm{Mg}^{2+}$ concentration used in $\mathrm{R} 1$ mediated the

dominance of the genera Methylophaga, Gelidibacter, Marinobacter and Brevundimonas with abundances of $32 \pm 3,12 \pm 34,8 \pm 2,8 \pm 2 \%$, respectively.

$<$ Figure 6>

The inoculum of R2, which was enriched from activated sludge, cow manure and soil, was composed mainly of Methylomicrobium and Methylophaga (41 \pm 5 and $21 \pm 4 \%$, 
respectively). However, Methylomicrobium represented only $15 \%$ of the total population by the end of the $\mathrm{C} 1$, value that remained constant until the end of experiment. Methylophaga, Marinobacter and Halomonas, which accounted for $16 \pm 2$, $25 \pm 4,26 \pm 3 \%$ of the total population by the end of $\mathrm{C} 1$ and $\mathrm{C} 2$, respectively, were able to compete better in this alkaline and saline environment than Methylomicrobium. The reduction in $\mathrm{Mg}^{2+}$ concentration resulted in a sharp increase of the dominance of a unknown uncultured family, previously isolated from mug, which represented $46 \pm 2 \%$ of the total bacterial community by the end of $\mathrm{C} 3$.

\section{Discussion}

\subsection{Ectoines production}

Magnesium exhibited a positive effect on the synthesis of ectoine regardless of the inoculum. Hence, 3 times higher ectoine yields were obtained at $0.2 \mathrm{mg} \mathrm{Mg}^{2+} \mathrm{L}^{-1}$ compared to those recorded at $0.002 \mathrm{mg} \mathrm{Mg}^{2+} \mathrm{L}^{-1}$, likely due to the effect of $\mathrm{Mg}^{2+}$ on the ectoine biosynthesis pathway or on protein expression, transcription and translation. In this context, other environmental parameters such as $\mathrm{NaCl}$, nitrogen, copper or the carbon source have been demonstrated to boost ectoine production when increasing their concentration ${ }^{24,33,34}$. Although the structure of bacterial population shifted as a function on $\mathrm{Mg}^{2+}$ concentration, most genera identified in R1 and R2 (i.e Marinobacter, Methylophaga or Halomonas) have been previously described as ectoine producers. For instance, the genus Halomonas can support ectoine accumulations of 150-170 $\mathrm{mg} \mathrm{g}$ biomass $^{-18}$.

The ability of a given microorganism to synthesize hydroxyectoine inhererently depends on its ability to produce ectoine, since hydroxyectoine formation typically occurs directly from the conversion of either ectoine or one of its metabolic 
intermediates ${ }^{35}$. In this context, $\mathrm{Mg}^{2+}$ could affect the ectoine production pathway without impacting on hydroxyectoine accumulation. It is noteworthy that hydroxyectoine was always detected in $\mathrm{R} 2$, but only present in $\mathrm{R} 1$ at low $\mathrm{Mg}^{2+}$ concentration. No hydroxyectoine accumulation has been reported to date in $M$. alcaliphilum $20 \mathrm{Z}$ cells grown at salinities up to $9 \% \mathrm{NaCl}^{11}$. This compatible solute is more common among gram-positive halophilic/halotolerant bacteria, although it is often co-synthesized with ectoine in a lower extent in many other ectoine-producing species (e.g. accumulations of 36.8 and $45 \mathrm{mg}$ hydroxyectoine $\mathrm{g}$ biomass $^{-1}$ have been reported in Halomonas boliviensis DSM 15516 and Halomonas elongata KS3, respectively $)^{33,36,37}$. Therefore, the production of hydroxyectoine in both reactors was probably due to the presence of other bacterial population in both consortia, such as the genera Halomonas, Methylophaga and Marinobacter. In brief, the co-production of several ectoines during $\mathrm{CH}_{4}$ abatement by a methanotrophic consortium composed of Halomonas, Marinobacter, Methylomicrobium and Methylophaga open up new opportunities for climate change mitigation.

\subsection{Bioplastic production}

Preliminary studies with methanotrophic bacteria suggested a positive effect of $\mathrm{Mg}^{2+}$ limitation on PHAs production. Thus, Wendland et al. $(2001)^{38}$ found PHAs contents of $28 \%\left(\mathrm{~g} \mathrm{~g}\right.$ biomass $\left.^{-1}\right)$ under $\mathrm{Mg}^{2+}$ limitation using a pure strain of Methylocystys sp. GB25, while PHAs contents of up to 50-60\% (g biomass) have been recently reported using Methylocystis parvus $O B B P$ under a $\mathrm{N}$ and $\mathrm{Mg}^{2+}$ limitation ${ }^{39,40}$. However, the PHAs contents recorded in this study were much lower than the ones reported by other authors using $\alpha$-proteobacter methanotrophs, since PHAs synthesis is supposed to be linked with the serine cycle. At this point it should be highlighted that despite nitrogen 
limitation increases PHAs production ${ }^{41}$, no nitrogen limitation was carried out in this study due to its negative effect on ectoine production, which has a higher profit margin than PHAs. Finally, the synthesis of PHA recorded during C3 in R1 could be directly attributed to the occurrence of the genera Brevundimonas and Pannonibacter under low $\mathrm{Mg}^{2+}$ concentrations, which are well known polyhydroxybutyrate producers $^{42,43}$.

\subsection{Exopolysaccharides production}

RuMP-pathway $\gamma$-proteobacter methanotrophs are able to support high productions of EPS. Thus, Malashenko et al. (2001) observed EPS yields ranging from 300 to 450 mg $\mathrm{g} \mathrm{biomass}^{-1}$ in $\gamma$-proteobacter methanotrophic cultures. In this context, the presence of Methylomicrobium and other $\gamma$-proteobacteria supports the high EPS yields obtained in this study. Moreover, previous studies have consistently demonstrated that stress conditions such as a high $\mathrm{pH}$ and high salinity can boost EPS biosynthesis ${ }^{44,45}$. Overall, the combination of a high alkalinity and salinity MSM with the occurrence of EPS producing microorganisms in the reactors resulted in EPS yields higher than those typically obtained in mesophilic methanotrophic cultures. However, the limitation in $\mathrm{Mg}^{2+}$ negatively affected the biosynthesis of exopolysaccharides.

\subsection{Methane abatement performance}

Significantly similar biomass concentrations were recorded in the reactors regardless of the $\mathrm{Mg}^{2+}$ concentration according to the TSS values. On the other hand, the mass transfer limitations tests carried out under steady state in $\mathrm{C} 1, \mathrm{C} 2$ and $\mathrm{C} 3$ demonstrated that both reactors were mass transfer limited despite the negative impact of $\mathrm{Mg}^{2+}$ 
limitation on microbial biosynthesis metabolism. The decrease in EC recorded in both reactors under low $\mathrm{Mg}^{2+}$ limitation, which was not caused by a deterioration in the $\mathrm{CH}_{4}$ biodegradation capacity of the community, was likely due to the biofouling of the gas diffusers in the reactor, which likely decreased the mass transfer capacity of the systems. The ECs and REs recorded in this study (ECs of XX-XX and YY-YY g m${ }^{-3} \mathrm{~h}^{-}$ 1, corresponding to REs of XX-XX and YY-YY \% in R1 and R2, respectively ) were in agreement with the ECs and REs reported in suspended-growth bioreactors operated with haloalkaliphilic methanotrophs, which typically range between 13.2 to $24.5 \mathrm{~g} \mathrm{~m}^{-3}$ $\mathrm{h}^{-1}$ (corresponding to REs of 22.5-31.3\%) ${ }^{9,10}$. However, these ECs and REs were lower than those obtained in conventional biofilters and biotrickling filters operated with mesophilic methanotrophs $\left(\mathrm{ECs}=65-280 \mathrm{~g} \mathrm{~m}^{-3} \mathrm{~h}^{-1}\right.$ corresponding to REs of 50-90 $\%)^{46,47}$. The lower elimination capacities here obtained were likely caused by both the detrimental effects of salt and alkalinity on methane solubility, which decrease methane mass transfer from the gas emission to the microorganisms, and the less effective metabolism of extremophiles microorganisms ${ }^{48,49}$.

Finally, it is worth noting that most genera identified in the R1 and R2 have not been previously identified as methane degraders. In fact, only the genus Methylomicrobium is considered methanotrophic. Therefore, the fact that $\mathrm{CH}_{4} \mathrm{ECs}$ were maintained roughly similar during the complete experiment suggested that other microorganisms present in the reactors were able to use $\mathrm{CH}_{4}$ as the only energy and carbon source.

\section{Conclusion}

This study fostered the potential of $\mathrm{CH}_{4}$ biorefineries by validating the multi-production of high added market value metabolites from diluted $\mathrm{CH}_{4}$ emissions. However, the 
decrease in $\mathrm{Mg}^{2+}$ concentration from 0.2 to $0.002 \mathrm{mg} \mathrm{L}^{-1}$ did not significantly enhance PHAs but resulted in a severe deterioration in the biosynthesis of ectoines and exopolysaccharides. The identification of novel methanotrophic consortia able to coproduce ectoine and hydroxyectoine using methane as the sole feedstock, in addition to exopolysaccharides, can make methane abatement much more cost-effective and help mitigating climate change. In this context, the use of mixed methanotrophic communities in $\mathrm{CH}_{4}$ biorefineries could provide more resilience and stability to the process while overcoming the current problems of metabolite productivity characteristic of M. alcaliphilum $20 Z$.

\section{Acknowledgments}

This research was supported by the Spanish Ministry of Economy and Competitiveness (CTM2015-70442-R project and Red NOVEDAR), the European Union through the FEDER Funding Program and the Regional Government of Castilla y León (PhD Grant contract No E-47-2014-0140696 and UIC71). Suní Rodriguez and Lidia Sadornil are also acknowledged for their practical assistance, and Sudarshan for his contribution to the NG-tax analysis.

\section{References}

(1) European Environment Agency. European environment - state and outlook 2015: Assessment of global megatrends; 2015.

(2) Agency, E. E. European Environment Agency: Data and Maps.

(3) (EPA), E. P. A. Green Enterprise - Environmental Protection Agency (EPA. Environ. Prot. Agency 2017.

(4) European Environmental Agency. Atmospheric greenhouse gas concentrations 
(CSI 013/CLIM 052) - Assessment published Feb 2015.

(5) Strong, P.; Laycock, B.; Mahamud, S.; Jensen, P.; Lant, P.; Tyson, G.; Pratt, S. The Opportunity for High-Performance Biomaterials from Methane.

Microorganisms 2016, 4 (1), 11.

(6) Strong, P. J.; Kalyuzhnaya, M.; Silverman, J.; Clarke, W. P. Bioresource Technology A methanotroph-based biorefinery : Potential scenarios for generating multiple products from a single fermentation. Bioresour. Technol. 2016.

(7) Khmelenina, V. N.; Rozova, N.; But, C. Y.; Mustakhimov, I. I.; Reshetnikov, A. S.; Beschastnyi, A. P.; Trotsenko, Y. A. Biosynthesis of secondary metabolites in methanotrophs: biochemical and genetic aspects (review). Appl. Biochem. Microbiol. 2015, 51 (2), 150-158.

(8) Pastor, J. M.; Salvador, M.; Argandoña, M.; Bernal, V.; Reina-Bueno, M.; Csonka, L. N.; Iborra, J. L.; Vargas, C.; Nieto, J. J.; Cánovas, M. Ectoines in cell stress protection: Uses and biotechnological production. Biotechnol. Adv. 2010, $28(6), 782-801$.

(9) Cantera, S.; Lebrero, R.; Rodríguez, S.; García-Encina, P. A.; Muñoz, R. Ectoine bio-milking in methanotrophs: A step further towards methane-based biorefineries into high added-value products. Chem. Eng. J. 2017, 328, 44-48.

(10) Cantera, S.; Lebrero, R.; Rodríguez, E.; Garcia-Encina, P. A.; Muñoz, R. Continuous abatement of methane coupled with ectoine production by Methylomicrobium alcaliphilum 20Z in stirred tank reactors: A step further towards greenhouse gas biorefineries. J. Clean. Prod. 2017, 152.

(11) Reshetnikov, A. S.; Khmelenina, V. N.; Mustakhimov, I. I.; Trotsenko, Y. A. Genes and enzymes of Ectoine biosynthesis in halotolerant methanotrophs. 
Methods Enzymol. 2011, 495, 15-30.

(12) Castilho, L. R.; Mitchell, D. A.; Freire, D. M. G. Production of polyhydroxyalkanoates (PHAs) from waste materials and by-products by submerged and solid-state fermentation. Bioresour. Technol. 2009, 100 (23), 5996-6009.

(13) Chen, G. Q.; Hajnal, I.; Wu, H.; Lv, L.; Ye, J. Engineering Biosynthesis Mechanisms for Diversifying Polyhydroxyalkanoates. Trends in Biotechnology. 2015, pp 565-574.

(14) Pieja, A. J.; Sundstrom, E. R.; Criddle, C. S. Cyclic, alternating methane and nitrogen limitation increases PHB production in a methanotrophic community. Bioresour. Technol. 2012, 107, 385-392.

(15) Zhang, T.; Zhou, J.; Wang, X.; Zhang, Y. Coupled effects of methane monooxygenase and nitrogen source on growth and poly-??-hydroxybutyrate (PHB) production of Methylosinus trichosporium OB3b. J. Environ. Sci. (China) $\mathbf{2 0 1 7}, 52,49-57$.

(16) Rahnama F, Vasheghani-Farahania E, Yazdian F, S. S. PHB production by Methylocystis hirsuta from natural gas in a bubble column and a vertical loop bioreactor. Biochem. Eng. J. 2012, 65, 51-56.

(17) Flemming, H.; Wingender, J. The biofilm matrix. Nat. Rev. Microbiol. 2010, 8 (9), 623-633.

(18) Nwodo, U. U.; Green, E.; Okoh, A. I. Bacterial exopolysaccharides: Functionality and prospects. International Journal of Molecular Sciences. 2012, pp 14002-14015.

(19) Malashenko, I. P.; Pirog, T. P.; Romanovskaia, V. a; Sokolov, I. G.; Gringerg, T. a. Search for methanotrophic producers of exopolysaccharides. Prikl. Biokhim. 
Mikrobiol. 2001, 37 (6), 702-705.

(20) Kalyuzhnaya, M. G.; Khmelenina, V.; Eshinimaev, B.; Sorokin, D.; Fuse, H.; Lidstrom, M.; Trotsenko, Y. Classification of halo(alkali)philic and halo(alkali)tolerant methanotrophs provisionally assigned to the genera Methylomicrobium and Methylobacter and emended description of the genus Methylomicrobium. Int. J. Syst. Evol. Microbiol. 2008, 58 (3), 591-596.

(21) Khanna, S.; Srivastava, A. K. Recent advances in microbial polyhydroxyalkanoates. Process Biochemistry. 2005, pp 607-619.

(22) Nikiema, J.; Brzezinski, R.; Heitz, M. Elimination of methane generated from landfills by biofiltration: a review. Rev. Environ. Sci. Biotechnol. 2007, 6, 261284.

(23) Lebrero, R.; Hernández, L.; Pérez, R.; Estrada, J. M.; Muñoz, R. Two-liquid phase partitioning biotrickling filters for methane abatement: Exploring the potential of hydrophobic methanotrophs. J. Environ. Manage. 2015, 151, 124131.

(24) Cantera, S.; Lebrero, R.; Sadornil, L.; García-encina, P. A.; Mu, R. Valorization of $\mathrm{CH} 4$ emissions into high-added-value products : Assessing the production of ectoine coupled with CH 4 abatement. J. Environ. Manage. 2016, 182, 160-165.

(25) American Water Works Association. Standard Methods for the Examination of Water and Wastewater; 2012.

(26) Tanimura, K.; Nakayama, H.; Tanaka, T.; Kondo, A. Ectoine production from lignocellulosic biomass-derived sugars by engineered Halomonas elongata. Bioresour. Technol. 2013, 142, 523-529.

(27) López, J. C.; Quijano, G.; Pérez, R.; Muñoz, R. Assessing the influence of CH4 concentration during culture enrichment on the biodegradation kinetics and 
population structure. J. Environ. Manage. 2014, 146, 116-123.

(28) Qurashi, A. W.; Sabri, A. N. Bacterial exopolysaccharide and biofilm formation stimulate chickpea growth and soil aggregation under salt stress. Brazilian J. Microbiol. 2012, 43 (3), 1183-1191.

(29) Walters, W.; Hyde, E. R.; Berg-Lyons, D.; Ackermann, G.; Humphrey, G.; Parada, A.; Gilbert, J. A.; Jansson, J. K.; Caporaso, J. G.; Fuhrman, J. A.; et al. Improved Bacterial 16S rRNA Gene (V4 and V4-5) and Fungal Internal Transcribed Spacer Marker Gene Primers for Microbial Community Surveys. mSystems 2016, 1 (1), e00009-15.

(30) Ramiro-Garcia, J.; Hermes, G. D. A.; Giatsis, C.; Sipkema, D.; Zoetendal, E. G.; Schaap, P. J.; Smidt, H. NG-Tax, a highly accurate and validated pipeline for analysis of 16S rRNA amplicons from complex biomes. F1000Research 2016, 5, 1791.

(31) Quast, C.; Pruesse, E.; Yilmaz, P.; Gerken, J.; Schweer, T.; Yarza, P.; Peplies, J.; Glöckner, F. O. The SILVA ribosomal RNA gene database project: Improved data processing and web-based tools. Nucleic Acids Res. 2013, 41 (D1).

(32) Cantera, S.; Estrada, J. M.; Lebrero, R.; García-Encina, P. A.; Muñoz, R. Comparative performance evaluation of conventional and two-phase hydrophobic stirred tank reactors for methane abatement: Mass transfer and biological considerations. Biotechnol. Bioeng. 2016, 113 (6), 1203-1212.

(33) Salar-García, M. J.; Bernal, V.; Pastor, J. M.; Salvador, M.; Argandoña, M.; Nieto, J. J.; Vargas, C.; Cánovas, M. Understanding the interplay of carbon and nitrogen supply for ectoines production and metabolic overflow in high density cultures of Chromolobacter salexigens. Microb. Cell Fact. 2017, 16 (1), 23.

(34) Khmelenina, Y. N.; Eshinimaev, B. T.; Kalyuzhnaya, M. G.; Trotsenko, Y. a. 
Potential activity of methane and ammonium oxidation by methanotrophic communities from the soda lakes of southern Transbaikal. Microbiology 2000, 69 (4), 460-465.

(35) Bursy, J.; Pierik, A. J.; Pica, N.; Bremer, E. Osmotically induced synthesis of the compatible solute hydroxyectoine is mediated by an evolutionarily conserved ectoine hydroxylase. J. Biol. Chem. 2007, 282 (43), 31147-31155.

(36) Van-Thuoc, D.; Guzmán, H.; Quillaguamán, J.; Hatti-Kaul, R. High productivity of ectoines by Halomonas boliviensis using a combined two-step fed-batch culture and milking process. J. Biotechnol. 2010, 147 (1), 46-51.

(37) Fallet, C.; Rohe, P.; Franco-Lara, E. Process optimization of the integrated synthesis and secretion of ectoine and hydroxyectoine under hyper/hypo-osmotic stress. Biotechnol Bioeng 2010, 107.

(38) Wendlandt, K. D.; Jechorek, M.; Helm, J.; Stottmeister, U. Producing poly-3hydroxybutyrate with a high molecular mass from methane. J. Biotechnol. 2001, $86(2), 127-133$.

(39) Myung, J.; Kim M; Pan, M.; Criddle, C. S.; Tang, S. Low energy emulsion-based fermentation enabling accelerated methane mass transfer and growth of poly(3hydroxybutyrate)-accumulating methanotrophs. Bioresour. Technol. 2016, 207, $302-307$.

(40) Rostkowski, K. H.; Pfluger, A. R.; Criddle, C. S. Stoichiometry and kinetics of the PHB-producing Type II methanotrophs Methylosinus trichosporium OB3b and Methylocystis parvus OBBP. Bioresour. Technol. 2013, 132, 71-77.

(41) García-Pérez, T.; López, J. C.; Passos, F.; Lebrero, R.; Revah, S.; Muñoz, R. Simultaneous methane abatement and PHB production by Methylocystis hirsuta in a novel gas-recycling bubble column bioreactor. Chem. Eng. J. 2018, 334, 
$691-697$.

(42) Bhuwal, A. K.; Singh, G.; Aggarwal, N. K.; Goyal, V.; Yadav, A. Isolation and screening of polyhydroxyalkanoates producing bacteria from pulp, paper, and cardboard industry wastes. Int. J. Biomater. 2013, 2013.

(43) Ray, S.; Prajapati, V.; Patel, K.; Trivedi, U. Optimization and characterization of PHA from isolate Pannonibacter phragmitetus ERC8 using glycerol waste. Int. J. Biol. Macromol. 2016, 86, 741-749.

(44) Matsumoto, T.; Yamamura, H.; Hayakawa, J.; Watanabe, Y.; Harayama, S. Influence of extracellular polysaccharides (EPS) produced by two different green unicellular algae on membrane filtration in an algae-based biofuel production process. Water Sci. Technol. 2014, 69 (9), 1919 LP-1925.

(45) Ates, O. Systems Biology of Microbial Exopolysaccharides Production. Front. Bioeng. Biotechnol. 2015, 3.

(46) Park, S.; Lee, C. H.; Ryu, C. R.; Sung, K. Biofiltration for reducing methane emissions from modern sanitary landfills at the low methane generation stage. Water. Air. Soil Pollut. 2009, 196 (1-4), 19-27.

(47) Josiane, N.; Michèle, H. The influence of the gas flow rate during methane biofiltration on an inorganic packing material. Can. J. Chem. Eng. 2009, 87 (1), $136-142$.

(48) Rampelotto, P. Extremophiles and Extreme Environments. Life 2013, 3 (3), 482 485.

(49) Duan, Z.; Mao, S. A thermodynamic model for calculating methane solubility, density and gas phase composition of methane-bearing aqueous fluids from 273 to $523 \mathrm{~K}$ and from 1 to 2000 bar. Geochim. Cosmochim. Acta 2006, 70 (13), $3369-3386$. 
